\title{
Aligning Price Regulation with Telecommunications Competition
}

\author{
TIMOTHY J. TARDIFF* \\ National Economic Research Associates \\ WILLIAM E. TAYLOR \\ National Economic Research Associates
}

\begin{abstract}
Since the 1990s, local exchange telecommunications carriers (LECs) have been subject to incentive regulation plans. This paper discusses theoretical and practical aspects of the evolution of price regulation as retail competition increases and as regulators mandate extensive availability of wholesale services. Particular issues include (1) adjusting price change/productivity expectations as the proportion of services subject to price regulation decreases, (2) whether earnings sharing is compatible with more limited price regulation, and (3) compatibility among wholesale and retail price and quality regulation. The paper concludes by describing recent developments in specific jurisdictions and recommends directions for future incentive regulation.
\end{abstract}

\section{Introduction}

Shortly after passage of the Telecommunications Act in 1996, but before the release of the Federal Communication Commission's (FCC, 1996) landmark order that implemented the local competition provisions of the Act, we reviewed the rapid evolution from traditional cost-of-service regulation to price-based incentive regulation that had been attained in the first part of the 1990s (Tardiff and Taylor, 1996). In roughly half a decade, well over half of state regulators as well as the FCC had instituted new plans for pricing the services of local exchange carriers (LECs), with "I - X" price cap regulation being the modal form of this new regulatory approach. ${ }^{1}$ Further, there appeared to be widespread agreement on the theory and methods of establishing key parameters, such as expected level of annual

\footnotetext{
* Contact author. Mailing address: National Economic Research Associates, One Main Street, Cambridge, MA 02142, USA. E-mail address: timothy.tardiff@nera.com An earlier version of this paper was presented at the Advanced Workshop in Regulation and Competition, $22^{\text {nd }}$ Annual Conference, Skytop, Pennsylvania, May 22, 2003.

${ }^{1}$ In such price cap plans, the regulated firm's prices are capped each year and the level of the cap is last year's cap, increased by inflation in the overall economy, but adjusted for productivity differences between the average firms in the overall economy and the industry being regulated. For example, if inflation were 2 percent and the regulated industry were deemed to be 3 percent more productive than firms in the overall economy, the price cap would decrease by one percent.
} 
productivity ("X factor), with disputes over the particular value focusing on details rather than approach. At the same time, we noted that concurrently with the initial emergence of competition for regulated local exchange services - competition that the Act itself was intended to promote - there were some initial movements towards newer approaches intended to focus price protection on services with insufficient competition with concomitant relaxation of regulation and/or deregulation of other services subject to "sufficient" competition. ${ }^{2}$

Because of the new extensive requirements imposed by the Telecommunications Act, ${ }^{3}$ state regulators necessarily shifted attention away from investigating incentive regulation plans. Renewed attention and subsequent revisions of particular plans have been undertaken only relatively recently in a number of states. ${ }^{4}$ During what was in effect a hiatus in regulatory action on incentive regulation issues in the last half of the 1990s, not only did local competition grow but there were also some theoretical advances on the issue of how regulation of the services of former regulated monopoly providers of local exchange services should evolve apace with such competition. These developments are the focus of the rest of this paper.

The remainder of this paper is organized as follows. In the next section, we review the major distinctions between traditional cost-of-service regulation and the early versions of incentive regulation. We then describe recent trends in local exchange competition and LEC productivity performance as motivation for theoretical and practical changes in incentive regulation. The fourth section describes recent theoretical developments in the economics of incentive regulation and the subsequent section presents several examples of the evolution of price cap plans in particular states. The final section presents our conclusions.

\section{The transition from cost of service to incentive regulation}

The rationale for and characteristics of the incentive regulation plans that emerged by the mid 1990s have been reviewed extensively elsewhere. ${ }^{5}$ For purpose of this discussion it is useful to identify some of the major themes. While both traditional regulation and incentive regulation shared the common rationale of attempting to establish regulation that would emulate the outcomes of competition if it were feasible, the particular outcomes differed: overall profits with traditional regulation versus overall prices for incentive regulation. Because profit regulation can have bad incentive properties (why worry about

\footnotetext{
${ }^{2}$ In particular, we reviewed new variations on the standard "I - X" approach that had been proposed and/or adopted in Canada and California.

${ }^{3}$ State regulators have been heavily involved in establishing prices for unbundled network elements that the Act requires incumbent LECs to make available to competitors, reviewing requests by these incumbents for authority to offer long-distance service in their regions, and early on in determining whether to establish explicit state-authorized universal service subsidy programs.

${ }^{4}$ The FCC did complete a review of its price cap index (resulting among other changes in a higher "X factor) and some restructuring of its plan for regulating LECs' interstate services in 1997 (FCC (1997a and 1997b). The price cap decision was subsequently overturned and remanded back to the FCC. Before it completed the mandated review, parties settled on a new price regulation plan, whose major feature included a multiyear transition towards cost-based rates, further restructuring of rates, and increased universal service funding. (FCC, 2000). The plan no longer ties price changes explicitly to the traditional "I - X" index.

${ }^{5}$ Two recent comprehensive discussions are Vogelsang (2002) and Sappington (2002).
} 
reducing costs when they are effectively passed through to prices) and may be conducive to anticompetitive cross subsidization (below-cost prices could both be recouped by higher prices for less-competitive services and at the same time could expand the rate base that determines total profits), price regulation has been shown to have better incentive properties and to be free of the perverse anticompetitive incentives. ${ }^{6}$ Further, incentive regulation lessens regulatory costs, because investment and operating decisions are left to the discretion of management, rather than being subject of after-the-fact prudence reviews under traditional regulation. ${ }^{7}$

While some of the earlier plans recognized potential differences in competitive conditions for different services, primarily by grouping services into different baskets for which separate caps and possibly different pricing rules prevailed, the basis for establishing the caps themselves did not recognize such differences. Instead, a single measure of expected price changes was used across the board. ${ }^{8}$ This perspective overlooks the possibilities that both competitive pressures and technological prospects could differ for different types of services. With regard to the latter, services whose costs consist primarily of "low tech" components, for example, as copper wires and telephone poles, may experience less productivity improvement (cost reduction) than other services that rely on computer-based components such as switches. In fact, the development of competition has not been uniform across services and customer groups, as we describe in the following section.

\section{Recent developments in local exchange competition and productivity}

The rationale for adjustments to current incentive regulation plans should and will be informed by both theory and real-world developments. In this section, we review recent developments in local competition, which are germane to the issue of whether incentive regulation plans should become more granular to accommodate competition in general and differences in competitive development, in particular. We then observe trends in output growth and productivity to explore whether limits on those prices still subject to price controls should be changed from those implied by current price cap plans.

\footnotetext{
${ }^{6}$ The latter is especially the case with respect to plans that do not call for earnings sharing between ratepayers and shareholders. In fact, as of 2000, only one state (New Jersey) imposed such sharing on LECs (Sappington, 2002, Table 2). In 2002, the New Jersey Board of Public Utilities eliminated this sharing requirement.

${ }^{7}$ Interestingly, although regulators intentionally eschewed such micromanagement when regulating retail services, they have engaged in what seems to resemble a determination of prudence before the fact when they establish the wholesale prices for unbundled network elements. In particular, the FCC's costing standard requires in effect that regulators determine forward-looking investment and operations decisions. To the extent that incumbent LECs' actual practices differ, they would not be able to include such costs in wholesale prices. See, for example, Kahn, et al. (1999) and Tardiff (2000).

${ }^{8}$ For example, in plans utilizing a productivity target to index price caps annually, that target was based on an industry-wide average of the expected productivity of the firm as a whole, that is, if inflation were 2 percent and the "X factor" were 3 percent, prices on average were expected to decrease at one percent. While productivity is appropriately measured for the firm as a whole, that productivity does not necessarily imply that the expected changes in the prices of the firms' individual products and services will be the same, as we discuss in the fourth section of this paper.
} 


\subsection{Local competition}

While the financial plight of the telecommunications industry, in general, and new competitors, such as competitive local exchange carriers (CLECs), in particular, has been the focus of recent attention, there is no doubt that competition has grown considerably. In it most recent report on local telephone competition, the FCC (2003) reports that competitors serve over 13 percent of all local exchange lines. This competition varies both geographically, for example, the FCC reports that CLECs serve one-quarter of all lines in New York state, as well as by customer type. In particular, the FCC's statistics show that while CLECs serve about 10 percent of residential and small business lines, they serve about 23 percent of large business lines, or more than double the small customer proportion. ${ }^{9}$

Local competition has grown considerably in recent years. The FCC considered the state of local competition in its 1999 and 2002 reviews of its rules for the availability of unbundled network elements. As part of those reviews, data on the growth of CLEC activity at both the national and regional levels was assembled. ${ }^{10}$ These data show that between the end of 1998 and the end of 2001, CLECs' volumes grew considerably, while at the same time incumbent local exchange carriers (ILECs) have actually lost lines. In particular:

- The number of lines served by CLECs wholly or partially over facilities they have deployed themselves tripled from between 5.0 - and 6.0 million in 1998 to between 16 and 23 million lines in 2001. ${ }^{11}$

- Voice switches owned by CLECs have increased from 700 to $1,300 .^{12}$

- CLEC fiber-optic facilities increased from 100,000 to 184,000 route-miles. ${ }^{13}$

In short, competition for local exchange services has developed and grown in a number of different ways. While some firms rely on inputs obtained from LECs (the implications of which we discuss below), other firms rely in whole or in part on their own facilities. Among the latter arrangements (which according to the FCC supply about 42 percent of the lines provided by CLECs), about 61 percent of those lines are supplied entirely with ILEC loops and switches. Indeed, the growth in technologies other than traditional copper wires has been strong. Since the end of 1999, wireless subscribership (which is becoming an increasingly attractive alternative to both traditional local and long-distance service) has grown by 70 percent - from 80 million to 136 million nationally. Another form of "intermodal" local competition is telephone service provided by local telephone companies, which grew from 1.1 million subscribers at the end of 2000 to 3.0 million subscribers by December 2002. Indeed, cable telephony now accounts for over 46 percent of the CLEC lines that do not require LEC inputs.

\footnotetext{
${ }^{9}$ The FCC defines large business customers as those with four or more lines at a location.

${ }^{10}$ In the most recent review, a prominent source was UNE Fact Report (2002).

${ }^{11}$ UNE Fact Report (2002, I-5), calculated at the middle of the range presented in Table 3 . This trend is broadly consistent with data reported by ALTS $(2002,17)$.

${ }^{12}$ UNE Fact Report $(2002$, I-1). ALTS $(2002,16)$ reports approximately the same figures: 579 in 1998 and 1,224 in 2001.

${ }^{13}$ UNE Fact Report (2002, I-1). (ALTS 2002, 17) reports an even greater increase: from 108,000 in 1998 to 340,000 in 2001.
} 


\subsection{Recent productivity trends}

In our previous review of the state of incentive regulation, we reported that the average " $\mathrm{X}$ factor" adopted by state regulators was just under three percent (Tardiff and Taylor, 1996: 27). Not surprisingly, because of the relative dearth of regulatory action on this issue, the average value has remained about the same; for example, one of us reported an average of 2.66 percent as of January 2001. ${ }^{14}$ The implication of this average and the recent average inflation rate of about 2 percent is that retail prices subject to price caps are expected to decline on the order of one percent or less annually. Examination of recent trends in LEC output growth and prices indicates that the currently adopted "X factors" are, if anything, ambitious expectations for the prospects of further LEC retail price declines.

It has often been noted that in an industry with scale and scope economies, such as telecommunications, higher output growth is conducive to higher productivity growth. Because of the health of the economy, in general, and the telecommunication industry, in particular in the latter part of the 1990s, output did in fact grow. For example, between the end of 1995 and 2000 the number of telephone lines provided by the larger LECs increased by about 16 percent, from about 120 million to about 140 million, fueled in part by second line growth to access the Internet. ${ }^{15}$ However, in 2001, these LECs lost 5.5 percent of their lines, which was almost enough to wipe out all growth they had enjoyed since $1997 .{ }^{16}$

In fact, output growth in general (not just access lines) has weakened in recent years. To illustrate this phenomenon, we use part of the FCC's total factor productivity (TFP) methodology, ${ }^{17}$ which combines the several categories of output - switched access lines, special access lines, local, intrastate, and interstate calling volumes - into a single quantity index. This index shows that RBOC output dropped by about 2 percent in $2001 .{ }^{18}$ The telecommunications market since its inception has been characterized by growth in output. These recent reductions in the average output of local exchange carriers are unprecedented.

It is also informative to compare output growth for the first three years of the period following the passage of the Telecommunications with the last three available years. The following table presents these results.

The table shows that annual output growth was on the order of five to six percent in the banner years from 1996-1998 and then dropped substantially in the most recent three years.

\footnotetext{
${ }^{14}$ Taylor (2001). Since that time a few states have discontinued or changed indexed price caps, for example, Massachusetts, New Jersey, and Kansas. The changes for these states has almost no effect on the average "X factor."

${ }^{15}$ In the data that follows in this section, the larger LECs are the territories served by the original Regional Bell Operating Companies (RBOCs). For examples, for Verizon, these figures account for the territories in the old NYNEX and Bell Atlantic territories, but not the territories served by the old GTE. We report these data to be consistent with the methodology the FCC formerly used when measuring productivity for its price cap plan.

${ }^{16}$ Preliminary data recently available from the FCC shows that the LECs continued to lose lines in 2002 . The large LECs (excluding Qwest, which, as of August 15, 2003, had not yet reported 2002 results) lost an additional 5.5 percent of their lines.

${ }^{17}$ FCC (1997b: Appendix D).

${ }^{18}$ During 2002, the RBOCs continued to lose output at even a faster rate. The preliminary data for 2002 (which as we described above excludes Qwest) shows that RBOC output declined by an additional 4 percent.
} 


$\begin{array}{cc}\text { Year } & \begin{array}{c}\text { Output quantity } \\ \text { Change }\end{array} \\ 1996 & 6.21 \% \\ 1997 & 4.84 \% \\ 1998 & 4.22 \% \\ 1999 & 4.77 \% \\ 2000 & 0.65 \% \\ 2001 & -1.79 \% \\ \mathbf{1 9 9 6 - 1 9 9 8} & 5.09 \% \\ \mathbf{1 9 9 9 - 2 0 0 1} & 1.21 \%\end{array}$

\section{Table 1: Annual growth in RBOC output}

Finally, as expected, the slower output growth translates into slower reduction in real prices, that is, a narrowing of the gap between output price changes for ILECs and for the overall economy. ${ }^{19}$ In particular, while the annual rate of inflation (as measured by GDPPI) increased by about 0.3 percent in the latest three years, the telephone industry output price trend increased by 1.7 percent (from -1.2 percent to 0.5 percent). As a result, the difference in the rate of output price changes decreased by one-half, to about 1.5 percent.

$\begin{array}{cccc}\text { Year } & \begin{array}{c}\text { RBOCs output } \\ \text { price }\end{array} & \text { GDP-PI } & \text { Difference } \\ 1996 & -1.25 \% & 1.92 \% & 3.17 \% \\ 1997 & -2.47 \% & 1.93 \% & 4.40 \% \\ 1998 & 0.06 \% & 1.22 \% & 1.16 \% \\ 1999 & -0.32 \% & 1.43 \% & 1.75 \% \\ 2000 & 0.85 \% & 2.08 \% & 1.23 \% \\ 2001 & 0.97 \% & 2.34 \% & 1.37 \% \\ \mathbf{1 9 9 6 - 1 9 9 8} & -1.22 \% & 1.69 \% & 2.91 \% \\ \mathbf{1 9 9 9 - 2 0 0 1} & 0.50 \% & 1.95 \% & 1.45 \%\end{array}$

Table 2: Comparison of RBOC and economy wide output price changes

Thus, the rate of productivity growth (as passed through to customers in the form of lower prices) has slowed in the current environment, and expectations formed in the mid1990s regarding real price decreases in the telecommunications industry may no longer be appropriate. ${ }^{20}$

\footnotetext{
${ }^{19}$ The RBOC output price index is total RBOC revenue normalized by the output quantity index presented in the previous table. The difference between this index and GDP-PI is a measure of the achieved differential between industry and economy-wide output price growth and, as such, is the historical analog to an average industry-wide "X factor."

${ }^{20}$ Again, the preliminary data show a continuation of the recent trend. Output prices for the RBOCs (excluding Qwest) decreased by about 0.8 percent in 2002, compared to an increase in GDP-PI of about 1.1 percent, producing a differential of about 1.9 percent.
} 


\subsection{Implications}

The trends in competition and local exchange industry performance have three potential implications for the modification of incentive regulation plans. First, both the growth of competition and the differences in growth for different services and customers indicate that price regulation may need to be refined to recognize differences in the degree and nature of competition. And, as we discuss in the next section, differences in both overall competitive inroads and the type of competition (facilities-based versus competition that depends on LEC-supplied wholesale inputs) have implications for modifying plans. Second, the controls on those prices still subject to price regulation should recognize possible differences in the likelihood that different groups of services can achieve and sustain price reductions. ${ }^{21}$ Third, the future health of the telecommunications industry - CLECs and ILECs alike - may well depend crucially on the retail price levels that competition and regulation produce, as cogently described by the FCC's Chairman, Michael Powell. In testimony before the U.S. Senate, he observed that the telecommunications industry had lost almost half a million jobs and about $\$ 2$ trillion of market value ${ }^{22}$ in two years (Powell, 2002). All sectors of the industry - long-distance, wireless, and incumbent local exchanges carriers - had suffered large declines in their market values - 68 percent, 71 percent, and 40 percent, respectively. These developments resulted in Chairman Powell's call for regulatory reform at both the state and federal level:

Finally, the long term prospects of the industry will not be bright if State and Federal policymakers do not continue to work hard and diligently to create genuine and viable economic and regulatory foundations for communications services growth and competition. Nowhere is this more pressing than in local markets. Currently, the cold fact remains that the economic foundations remain weak in local markets, especially for new entrants and increasingly for incumbents. Local firms, many of whom are being tasked with the chore of upgrading networks to provide one of the platforms to deliver broadband services, have little pricing flexibility for retail services. We, along with our State counterparts, must work together to improve these foundations through regulatory reform. For instance, we must consider rate rebalancing at the state level to provide carriers with greater pricing flexibility. We must continue to pursue doggedly the worthy universal service goals of ubiquity and affordability as new networks are deployed, based on sound economic principles. We must also provide incentives for more effective and sustainable competitive entry through our network access policies by providing incentives to new entrants and incumbents to produce an efficient wholesale market and by providing a regulatory framework that promotes competition, investment and innovation to deploy advanced networks.

\section{$4 \quad$ Recent theoretical developments}

Regulatory economists have long posited two fundamental principles concerning price regulation:

(1) that regulation should attempt to emulate the outcomes of competitive markets; for example, prices based on costs and firms facing proper incentives to lower costs and

\footnotetext{
${ }^{21}$ On the other hand, service-specific differences in regulatory treatment can raise administrative and incentive-compatibility problems.

22 To put this loss in perspective, the combined gross book value of incumbent local exchanges carriers was about $\$ 350$ billion at the end of 2000 , or only about one-sixth the industry's loss in market value. See FCC (2001).
} 
(2) for fully competitive markets, there should be no regulation of specific competitors. ${ }^{23}$

These tenets imply a continuum over which industries initially in need of regulation (that is, natural monopoly providers of services essential to consumers and/or competitors) are heavily regulated at first. Yet as competitive conditions change (essentially the erosion of the natural monopoly conditions that called for regulation), regulation itself must evolve in order for it to deliver the economic benefits that competition, supplemented by regulation where necessary, can bring. ${ }^{24}$ And that evolution entails both reducing the range of services still subject to regulation and replacing particular regulatory mechanisms when they are no longer effective. The end-state of this evolutionary continuum is full competition with no regulation. A corollary is that rather than being a necessary prerequisite for relaxed regulation (for example, elimination of earnings sharing), effective competition calls for the elimination of regulation itself for the services in question. In the remainder of this section, we describe recent developments regarding the transition to competition in the areas of (1) how to set price limits when only a subset of services are subject to price regulation, (2) whether earnings sharing is compatible with partial price regulation, and (3) whether retail regulation is necessary, when essential wholesale inputs are made available to entrants.

\subsection{Price limits for subsets of retail services}

A company-wide productivity factor, or $\mathrm{X}$ factor, is a statement about the expected price changes in the regulated firm's average prices. Jeffrey Bernstein and David Sappington ${ }^{25}$ have proposed a method for estimating an X-factor for a subset of a multi-product firm's services. ${ }^{26}$ The basic idea is straightforward - if (1) a standard total factor productivity study produces an $\mathrm{X}$-factor (productivity differential between a regulated industry and overall economy, augmented by any input price differential between the target industry and the economy) but (2) only a subset of services are subject to price cap controls, then arithmetic can be applied to produce the proper X-factor for the limited group of services.

An example shows how the approach works. Suppose an industry-wide productivity study (for example, TFP study) produces an X-factor of 3 percent. Suppose further that inflation in the economy (as measured by GDP-PI) is expected to average 2 percent over the period in which the proposed X-factor would apply. Suppose services not subject to the cap are expected to decline in price by 3 percent per year and these services account for one-half of the firm's output (measured as a revenue share). Then Bernstein-Sappington would work as follows:

\footnotetext{
${ }^{23}$ See, for example, Kahn (1988, I-17) and Baumol and Sidak (1994, 4-5). We discussed this issue in greater detail in Tardiff and Taylor (1996, 30-33).

${ }^{24}$ Technology and intermodal competition (for example, from wireless or cable companies) may erode the natural monopoly conditions entirely or might simply move them upstream, that is, from retail services to wholesale provision of network elements. In such cases, regulation of retail services may be relaxed with continued regulation of wholesale services.

${ }^{25}$ Bernstein and Sappington (1999). As we describe below, Professor Bernstein recently applied this method to support his recommendation for a new X-factor to be applied to a subset of SBC-Kansas's services (Kansas Corporation Commission Docket No. 02-GIMT-272-MIS).

${ }^{26}$ Bernstein and Sappington's method produces different expected prices changes (consistent with expected total factor productivity), but does not produce separate productivity measures for subsets of services. Total factor productivity growth is only defined for groups of outputs that are separable in production, and attempts to refine a productivity analysis will fail because of shared fixed costs.
} 
- The TFP study implies that average prices for the firm would be expected to decline by 1 percent annually (the 2 percent increase in GDP-PI, offset by the overall X-factor of 3 )

- Therefore, in order for overall prices to decline by 1 percent, capped prices would have to increase by 1 percent (because the weighted average of a 1 percent increase and a 3 percent decrease is a 1 percent decrease).$^{27}$

- The X-factor for the capped services is simply the difference between the expected change in GDP-PI and the price change calculated in the previous step. In this example, that difference is 2 percent minus 1 percent or 1 percent. That is, prices for the capped services would be expected to increase at a rate onepercentage point slower than the GDP-PI.

The Bernstein-Sappington approach can be viewed as a formal version of the commonsense notion that applying an across-the-board X-factor at the same time competitive pressure is causing some prices to decline would amount to double-counting the impacts of competition and regulatory price controls. When one set of prices is declining more (or increasing less), be it because of competition, because of unsustainable regulatory crosssubsidies or for whatever reason, basic arithmetic dictates that other prices must increase faster (or not decline as fast) as the overall average of the company's prices.

\subsection{Is earnings sharing compatible with partial regulation?}

When a firm supplies multiple services over a common network in an environment where these services face differing degrees of competition and regulation, determining what "optimal" pricing, investment, and operating decisions would be in a fully competitive market becomes exceedingly difficult, if not impossible. But that is the task that a regulator would implicitly assume when the terms of an incentive regulation plan call for profit, or earnings sharing. ${ }^{28}$ In particular, formulas that call for profit sharing can distort the investment decisions of the regulated firm, to the extent that the prices that can be charged and the profits that can be kept are less generous than they otherwise would be. And the extent to which competitors (many of which target packages of services to lucrative customers) are not constrained in their pricing, operating, and investment decisions, the competitive playing field is tilted in their direction.

Sharing mechanisms would introduce additional regulatory baggage, which in the worst case, would involve inherently arbitrary determinations of what proper earnings are and how they should be shared. This problem arises from the facts that (1) the profits to be shared should be limited to those associated with the services still needing protection, that is, the prices for these services (including the effects of sharing) should not depend on the success or failure of services not subject to regulation but (2) defining such "profits" for a firm that uses a single network to sell both price protected and other services is inherently arbitrary. Not only would proper values for familiar parameters such as economic

\footnotetext{
${ }^{27}$ In general, if $\mathrm{a}$ is the average price change implied by the overall $\mathrm{X}$-factor, $\mathrm{b}$ is the price change for noncapped services, and $\mathrm{s}$ is the share of output for non-capped services, then the expected price change for the capped services is $(a-s b) /(1-s)$. In our example, $a=-1$ percent, $s=0.5$, and $b=-3$ percent. Therefore, the general formula produces a result of $(-1-0.5(-3)) /(1-0.5)=(-1+1.5) / 0.5=1$.

${ }^{28}$ Even absent explicit earnings sharing, these difficulties can arise when the regulator effectively shares earnings ex post by adjusting the productivity offset for the future based in part on historical earnings.
} 
depreciation and cost of capital need to be established, but it would also be necessary to assign fractions of the costs of the network facilities (including shared costs and common overheads) to the protected services. The end result would almost certainly be an arbitrary measure of profits that would severely distort and hinder operating and investment decisions.

Further, such regulatory requirements would exacerbate the already unsettled economic and competitive environment that both incumbents and entrants face. In particular, in evaluating the potential profitability of investments in long-lived facilities, the prices that could be charged and the profits that would be realized would depend on the nature of the sharing mechanism, the details of the pricing regime (for example, the size of " $X$ " in an "I $-\mathrm{X}$ " formula), and the relative permanence and stability of each. ${ }^{29}$

\subsection{Has the Telecommunications Act made retail price regulation unnecessary?}

While the recent real-world difficulties of telecommunications firms have increased the urgency of pro-competitive regulatory policies, ${ }^{30}$ the theoretical validity has been recognized for some time. Chairman Powell's prescription for regulatory reform focuses on (1) the margin between the retail price and the prices charged to competitors for the wholesale services (for example, unbundled network elements) that will allow them to compete for retail customers and (2) whether the ensuing competition will afford both incumbents and entrants a reasonable opportunity to operate profitably. ${ }^{31}$ The practical implications are that unduly lowering the incumbents regulated retail prices (for example, through overly ambitious productivity targets and/or mandatory earnings sharing) will squeeze both the incumbents - because expected profits are lower - and the entrants because the margin between wholesale and retail prices leaves less room to compete.

Indeed, rather than continued tight regulation of retail prices, some economists have called for retail price deregulation when competitors have access to wholesale services provided by incumbents. For example, at the end of his term in which he was instrumental in formulating the FCC's pricing rules for unbundled network elements, then chief economist Joseph Farrell stated:

Smoothly functioning wholesale regulation...permits and indeed almost demands retail deregulation. If multiple providers can compete for a customer's business and promptly supply it at reasonable overall cost, even if they do so by leasing the incumbent's facilities, then it would seem that prompt deregulation of all charges to the provider's end-users will be appropriate... Indeed if regulators continue to regulate the incumbent's retail prices, and don't happen to replicate the

\footnotetext{
${ }^{29}$ This list of difficulties with earnings sharing in price cap plans in markets opened to competition is partly balanced by some offsetting effects that are difficult to quantify. In theory, earnings sharing gives the regulator (acting in loco parentis for the customer) a stake in the financial well-being of the regulated firm, which may discipline the regulators' choice of other important regulatory components, including easy of entry (Weisman, 1994). In practice, there is some evidence that prices for unbundled network elements (a principal means of entry) are lower in price cap states - all else equal - than in non-price cap states (Lehman and Weisman, 2000).

${ }^{30}$ See, for example, Powell (2002).

${ }^{31}$ Chairman Powell has been commenting on this issue throughout his chairmanship. For example, Telecommunications Reports, March 5, 2001, p. 10, attributed to him the following:
}

Retail rates are not an irrelevant part of an economic market, and regulators may have to make a choice between sustainable businesses for new market entrants and low prices for end users. 
solution that the incumbent and the customer find jointly most beneficial, it puts the incumbent at an artificial competitive disadvantage. ${ }^{32}$

Professor Farrell's position is similar to that of Professor Alfred Kahn, who has observed in more than one context, that because of the availability of wholesale services under the Telecommunications Act, effective competition now prevails in the incumbents' retailing operations:

What has yet to be generally remarked is that in telecommunications the obligations imposed on the ILECs by the Telecommunications Act and complementary state policies have come as close as conceivable to making the provision of telephone services at retail perfectly contestable and therefore regulation of the retail rates simply unnecessary. What these provisions do, at the extreme, is to reduce the sunk costs associated with entry into retailing close to zero....

The implications of this new situation are, nevertheless, dramatic. What it means, specifically, is that the typical requirements in governing statutes or regulations for reclassifying the entire range of retail local telephone services as competitive will, as a matter of economics, be satisfied by these rules. In these circumstances, deregulation of the retail operations of the ILECs becomes not just possible but mandatory. Effective competition demands that they have the identical freedom to compete at that level as is now enjoyed by their competitors... ${ }^{33}$

Kolesar and Weisman (2003) have recently presented a formal demonstration of the ideas articulated by Professors Farrell and Kahn. In particular, they demonstrated that when local exchange markets have been opened to competition through the availability of mandated wholesale elements at cost-based rates, a regulatorily-imposed upper limit on retail prices either has no impact on competitive outcomes (when it is set higher than the prices that competition would produce) or distorts competition in a deleterious manner ${ }^{34}$ (when the upper limit is too low). Based on this analysis, Weisman and Kolesar conclude that with accommodative entry policies, deregulation of retail markets is a better regulatory policy than maintaining limits on retail prices.

Thus, while economic theory has evolved, especially in its application to telecommunications markets, the pattern is clear: the opening of local exchange markets to competition (facilities-based or that made available by the provision of wholesale services, such as UNEs) makes continued regulation of retail markets increasingly problematic. By implication, any retrogression towards traditional regulation would be especially counterproductive. And, as described below, practice is advancing with theory: regulators in other states have recently revised incentive regulation plans consistently with these advancements in economic theory.

\section{$5 \quad$ Evolution of incentive regulation plans in practice}

While we are not aware of any regulator that has fully deregulated retail services (consistent with the economic arguments previously described), a number of states have used scheduled reassessments of price cap plans to take steps in that direction. In particular, (1) the services to which any form of price regulation is applied have been

\footnotetext{
${ }^{32}$ Farrell (1997). As a practical matter, when regulators have certified that local exchange markets are open to competition in the process of granting the incumbent long-distance authority under Section 271 , the conditions identified by Professor Farrell for deregulation of retail services would appear to have been met.

${ }^{33}$ Kahn, (1998, 56-58), footnotes excluded. Professor Kahn originally made this argument in Kahn (1997).

${ }^{34}$ In particular, an overly restrictive retail price limit will produce less entry and less investment in network facilities by both incumbents and entrants.
} 
narrowed primarily to access services for smaller customers, (2) the remaining services have been removed from price regulation, and (3) earnings sharing has either been eliminated or was not in effect in the previous plan.

This pattern is broadly consistent with good economic policy: regulation appears to be adapting - albeit slowly - to the degree of competition in the markets for individual services. A sticking point is basic access to the network. Regulators appear loath to relax control of basic exchange prices for residential and small business customers, despite the emergence of actual competition for these customers and the ease of entry due to resale and cost-based unbundled network elements.

Details for particular states follow.

\subsection{New Jersey}

The New Jersey Board of Public Utilities (2002) held a hearing on June 19, 2002, in order to decide on Verizon New Jersey's New Plan for Alternative Regulation. ${ }^{35}$ The Board used this hearing to decide the case in advance of the issuance of the Decisions and Order. Among the issues discussed in the hearing, where the Board approved a modified version of Verizon's plan, were the following:

- Verizon's plan included the reclassification of multi-line business services as competitive services, resulting in full pricing flexibility for those services (with a price floor requirement (p. 13).

- Verizon will be provided price flexibility to adjust rates by 10 percent per year for all services except basic line rate provided to customers with between two and four lines (p. 14).

- The new plan eliminates earnings sharing. (New Jersey was only state among the (approximately) 43 states having incentive regulation plans in which earnings sharing was in effect) (p. 18).

- Basic rates for residential subscribers remain frozen at current levels.

\subsection{Massachusetts ${ }^{36}$}

The Massachusetts Department of Telecommunications and Energy held a proceeding to review Verizon Massachusetts' price cap plan that was initiated in 1995 for a six-year term. After Verizon filed its proposed plan, the Department determined that the plan was, in effect, requesting classification of a large portion of its services as sufficiently competitive to permit market-based pricing. As a result, the Department split the investigation into two Phases. Phase I, completed on May 8, 2002, investigated Verizon's showing of sufficient competition in Massachusetts. In the recently-completed Phase II, the Department investigated and adopted a plan for regulatory treatment of Verizon's services

\footnotetext{
${ }^{35}$ After this article was submitted to the editors, the New Jersey Board released the Decisions and Order on August 19, 2003. It is available at $h$ htp://www.bpu.state.nj.us/wwwroot/telco/TO01020095\%208-1903.pdf

${ }^{36}$ For additional details, see Vasington (2003).
} 
that is consistent with the Department's findings in Phase I. Following is a list of issues addressed by the Department (2002) in its Phase I Order.

- The Department tentatively concluded that price increases for residential services should be limited to five percent per year, a rate increase that is less than the percentage price increases approved by the Department previously in 1990.

- The Department determined that Verizon will be granted upward pricing flexibility for private line services after special access services are moved to UNE-based pricing. In general, the Department stated that (1) services for which competing firms can use UNEs to compete are contestable, and therefore not subject to price regulation and (2) services that are not contestable on a UNE basis will not receive pricing flexibility.

- As part of pricing flexibility for business services, the Department permitted Verizon to geographically deaverage prices for business services.

In the Phase II Order, the Department (2003) (1) reaffirmed that business services (other than private line) are contestable, and therefore no longer in need of price regulation, (2) approved a revenue-neutral increase in basic residential service prices, and (3) adjusted the quality assurance program, which formerly had been linked to a companywide $\mathrm{X}$ factor.

\subsection{New York}

On February 8, 2002, the Department of Public Service Staff and Verizon (and most competitors) filed a joint proposal (settlement) for Verizon's regulatory plan. The New York Public Service Commission (2002) adopted this joint proposal and put in place the Verizon Incentive Plan (VIP) on February 27, 2002. Following is a list of issues addressed by the Commission in its Order.

- $\quad$ The proposed plan grants Verizon pricing flexibility for all services except (1) UNEs, (2) wholesale discounts, (3) interconnection and reciprocal compensation prices, (4) lifeline services, (5) maintenance and access to the ALI database, (6) directory assistance databases, (7) non-recurring connection charges, and (8) services previously offered free of charge, such as call blocking or PIC freezes. There is no cap for increases except for flat residential services. The total increase to the price of flat residential service cannot be more than $\$ 2.00-\$ 3.00$ in one year depending on the year of the plan and the rate group.

- Overall revenue increases associated with pricing flexibility are capped at $3 \%$ on an annualized basis.

- The Commission stated "with respect to retail rate flexibility, we are persuaded that the limited flexibility accorded Verizon in the VIP will enable it to respond to competitive pressures without rendering rates unreasonable."

- The Commission also noted that the terms of the VIP will "significantly enhance" the conditions for local telecommunications competition in New York. 


\section{$5.4 \quad$ Rhode Island}

On January 10, 2003, the Rhode Island Commission (2003) approved a modified alternative regulation plan and settlement agreement for Verizon - Rhode Island. The basic changes in the plan include

- The elimination of an inflation-minus-X annual adjustment to the price cap index.

- Pricing flexibility for business services, including business basic exchange service, subject only to a long run incremental cost price floor.

- A maximum of an annual $\$ 1$ per month increase in basic residential prices for two years with an option for a third year.

- An annual maximum price change for non-basic residential services, ranging from 5 to 15 percent.

- Earnings sharing had been part of earlier price cap plans in Rhode Island but had been abandoned in 1996.

\subsection{Kansas}

The Bernstein-Sappington method for establishing price limits for a subset of services was introduced in the Kansas Corporation Commission's review of Southwestern Bell's price cap plan, which heretofore had employed a single productivity factor. Professor Bernstein (2002) used his method to conclude that while application of the FCC's X factor methodology indicates that prices on average had declined about five percent faster than the GDP-PI, ${ }^{37}$ prices for non-basic services, which Southwestern Bell recommended be removed from price regulation, had declined in price relative to basic services. Therefore, a smaller productivity factor, which Professor Bernstein estimated to be about one percent, is implied for basic services. The Commission subsequently approved a settlement to the case that included a differential X factor for basic and non-basic services: (1) relaxing (but not removing from price regulation) controls on non-basic service and (2) including an $\mathrm{X}$ factor for basic services that was lower than what a industry-wide study would have produced, but higher than Professor Bernstein's result. ${ }^{38}$

\section{Conclusion}

Developments since the mid-1990s in local exchange competition, the overall condition of the telecommunications industry, and in economic thinking on how to regulate an industry in transition to greater competition have started to influence the terms and conditions of incentive regulation plans. In several states, plans have been changed so that (1) only services facing insufficient competition are subject to price controls and (2) the limits on these prices are no longer based on measures of average expected productivity. Both economic reasoning and public policy, for example, the Telecommunications Act,

\footnotetext{
${ }^{37}$ Professor Bernstein's data ended in 1998, before the downturn in the telecommunications industry. Therefore, the level of industry-wide productivity indicated by that data is too high.

${ }^{38}$ Kansas Corporation Commission (2002).
} 
recognize that sufficient competition calls for relaxed regulation and eventual deregulation of all services. In the interim, how regulators react to the proposition that mandated availability of essential wholes inputs calls for deregulation of retail services (as Massachusetts regulators did for most business services) will be of great interest, both in theory and practice.

\section{$7 \quad$ References}

ALTS (2002) The State of Local Competition 2002, April.

Baumol, William J. and J. Gregory Sidak (1994) Toward Competition in Local Telephony, The MIT Press: Cambridge.

Bernstein, Jeffrey I. (2001) Direct Testimony before the Kansas Corporation Commission, Docket No. 02-GIMT-272-MIS, April 1.

Bernstein, Jeffrey I. and David E. Sappington (1999) "Setting the X Factor in Price Cap Regulation," Journal of Regulatory Economics, 16: 5-25.

Farrell, Joseph (1997) "Prospects for Deregulation in Telecommunications (revised version),” May 30. (http://www.fcc.gov/Bureaus/OPP/Speeches/jf050997.html).

Federal Communications Commission (1996) Implementation of the Local Competition Provisions in the Telecommunications Act of 1996, CC Docket No. 96-98, First Report and Order, August 8.

Federal Communications Commission (1997a) Access Charge Reform, CC Docket No. 96262, Price Cap Performance Review for Local Exchange Carriers, CC Docket No. 94-1, Transport Price Restructure, CC Docket No. 91-213, and End User Common Line Charges, CC Docket No. 95-72, First Report and Order, May 16.

Federal Communications Commission (1997b) Price Cap Performance Review for Local Exchange Carriers, CC Docket No. 94-1 and Access Charge Reform, CC Docket No. 96262, Fourth Report and Order in CC Docket No. 94-1 and Second Report and Order in CC Docket No. 96-262, May 21.

Federal Communications Commission (2000) Access Charge Reform, CC Docket No. 96262, Price Cap Performance Review for Local Exchange Carriers, CC Docket No. 94-1, Low-Volume Long Distance Users, CC Docket No. 99-249, and Federal-State Joint Board on Universal Service, CC Docket No. 96-45, Sixth Report and Order in CC Dockets Nos. 96-262 and 94-1, Report and Order in CC Docket No. 99-249, and Eleventh Report and Order in CC Docket No. 96-45, May 31.

Federal Communications Commission (2001) Statistics of Communications Common Carriers, 2000/2001 Edition. 
Federal Communications Commission (2003) Local Telephone Competition: Status as of December 31, 2002, Industry Analysis and Technology Division, Wireline Competition Bureau, June.

Kahn, Alfred E. (1988) The Economics of Regulation, The MIT Press: Cambridge.

Kahn, Alfred E (1997) Statement in Support of Southern New England Telecommunications Corporation and The Southern New England Telephone Company's Proposed Reorganization, March 24.

Kahn, Alfred E. (1998) Letting Go: Deregulating the Process of Deregulation, Michigan State University Institute of Public Utilities.

Kahn, Alfred E., Timothy J. Tardiff, and Dennis L. Weisman (1999) "The Telecommunications Act at Three Years: An Economic Evaluation of Its Implementation by the Federal Communications Commission," Information Economics and Policy, 11: 319-365.

Kansas Corporation Commission (2002) Order Approving Joint Stipulation and Agreement, Docket No. 02-GIMT-272-GIT, June 17.

Lehman, Dale E. and Dennis L. Weisman, (2000), The Telecommunications Act of 1996: The 'Costs' of Managed Competition, The American Enterprise Institute: Washington D.C. and Kluwer Academic Publishers: New York.

Kolesar, Mark and Dennis L. Weisman (2003) "Accommodative Competitive Entry Policies and Telecommunications Regulation," Info - The journal of policy, regulation and strategy for telecommunications, 5: 34-40.

Massachusetts Department of Telecommunications and Energy (2002), DTE 01-31-Phase I, Investigation by the Department of Telecommunications and Energy on its own Motion into the Appropriate Regulatory Plan to succeed Price Cap Regulation for Verizon New England, Inc. d/b/a Verizon Massachusetts' intrastate retail telecommunications services in the Commonwealth of Massachusetts, May 8.

Massachusetts Department of Telecommunications and Energy (2003) DTE 01-31-Phase II, Investigation by the Department of Telecommunications and Energy on its own Motion into the Appropriate Regulatory Plan to succeed Price Cap Regulation for Verizon New England, Inc. d/b/a Verizon Massachusetts' intrastate retail telecommunications services in the Commonwealth of Massachusetts, April 11.

New Jersey Board Of Public Utilities (2002) Board Meeting in Docket No. T001020095 In the Matter of the Application of Verizon-New Jersey, Inc. for Approval (i) of a New Plan for an Alternative Form of Regulation and (ii) to Reclassify Multi-Line Rate Regulated Business Services as Competitive Services, and Compliance Filing, June 19.

New York Public Service Commission (2002) Order Instituting Verizon Incentive Plan, Cases 00-C-1945 and 98-C-1357, February 27. 
Powell, Michael K. (2001) Quoted in Telecommunications Reports, March 5: 10.

Powell, Michael K. (2002) Written Statement on "Financial Turmoil in the Telecommunications Marketplace: Maintaining the Operations of Essential Communications," Before the Committee on Commerce, Science, and Transportation, United States Senate, July 30.

Rhode Island (2003) State Of Rhode Island And Providence Plantations Public Utilities Commission, In Re: Verizon-Rhode Island's Alternative Regulation Plan: Docket No. 3445, Report And Order, January 10.

Sappington, David E.M. (2002) "Price Regulation," in Cave, Martin E. Sumit K. Majumdar, and Ingo Vogelsang, eds., Handbook of Telecommunications Economics, Amsterdam: Elsevier.

Tardiff, Timothy J. (2000) "Cost Standards for Efficient Competition," in Crew, Michael A., ed., Expanding Competition in Regulated Industries, Boston: Kluwer.

Tardiff, Timothy J. and William E. Taylor (1996) "Revising Price Caps: the Next Generation of Incentive Regulation Plans," in Crew, Michael E., ed., Pricing and Regulatory Innovations Under Increasing Competition, Kluwer: Boston: 21-38.

Taylor, William E. (2001) Testimony before the Maine Public Utilities Commission, Docket No. 99-851, January 8.

UNE Fact Report (2002) Prepared for and Submitted by BellSouth, SBC, Qwest, and Verizon, Federal Communications Commission, Review of the Section 251 Unbundling Requirements of Incumbent Local Exchange Carriers, CC Docket No, 01-338, Implementation of the Local Competition Provisions in the Telecommunications Act of 1996, CC Docket No. 96-98, and Deployment of Wireline Services Offering Advanced Telecommunications Capabilities, CC Docket No. 98-147, April 5.

Vasington, Paul (2003) "Incentive Regulation in Practice: A Massachusetts Case Study," Review of Network Economics, (current issue).

Vogelsang, Ingo (2002) "Incentive Regulation and Competition in Public Utility Markets: A 20-Year Perspective," Journal of Regulatory Economics, 4: 5-27.

Weisman, Dennis L. (1994) "Why Less May Be More Under Price Cap Regulation," Journal of Regulatory Economics, 6: 339-362. 